\title{
BMJ Open Patterns of benzodiazepine prescription among older adults in Switzerland: a cross-sectional analysis of claims data
}

\author{
Xhyljeta Luta (D , , ${ }^{1}$ Christophe Bagnoud, ${ }^{2}$ Mark Lambiris, ${ }^{3}$ Anne Decollogny, ${ }^{1}$ \\ Yves Eggli, ${ }^{1}$ Marie-Annick Le Pogam (D) , ${ }^{1}$ Pedro Marques-Vidal, ${ }^{4}$ \\ Joachim Marti (1) ${ }^{1}$
}

To cite: Luta X, Bagnoud C, Lambiris $\mathrm{M}$, et al. Patterns of benzodiazepine prescription among older adults in Switzerland: a cross-sectional analysis of claims data. BMJ Open 2020;10:e031156. doi:10.1136/ bmjopen-2019-031156

- Prepublication history and additional material for this paper are available online. To view these files, please visit the journal online (http://dx.doi. org/10.1136/bmjopen-2019031156).

Received 22 April 2019 Revised 04 November 2019 Accepted 06 November 2019

Check for updates

(C) Author(s) (or their employer(s)) 2020. Re-use permitted under CC BY-NC. No commercial re-use. See rights and permissions. Published by BMJ.

${ }^{1}$ Centre for Primary Care and Public Health (Unisanté), University of Lausanne, Lausanne, Switzerland

${ }^{2}$ Groupe Mutuel, Martigny,

Switzerland

${ }^{3}$ Swiss Tropical and Public Health Institute, Basel,

Switzerland

${ }^{4}$ Department of Internal Medicine, Lausanne University Hospital, Lausanne, Vaud, Switzerland

Correspondence to Professor Joachim Marti; joachim.marti@unisante.ch

\section{ABSTRACT}

Objective This study aimed to examine the prevalence and determinants of benzodiazepine prescription among older adults in Switzerland, and analyse association with hospitalisation and costs.

Design Retrospective analysis of claims data.

Setting The study was conducted in nine cantons in Switzerland.

Participants Older adults aged 65 years and older enrolled with a large Swiss health insurance company participated in the study.

Primary and secondary outcome measures The primary outcome was prevalence of benzodiazepine prescription. The secondary outcomes were (1) determinants of any benzodiazepine prescription; (2) the association between any prescription and the probability of hospitalisation for trauma and (3) the association between any prescription and total healthcare expenditures.

Results Overall, 69005 individuals were included in the study. Approximately $20 \%$ of participants had at least one benzodiazepine prescription in 2017. Prescription prevalence increased with age (65-69: 15.9\%; 70-74: 18.4\%; 75-80: 22.5\%; >80: 25.8\%) and was higher in women (25.1\%) compared with men (14.6\%). Enrollees with the highest deductible of Swiss Francs (CHF) 2500 were $70 \%$ less likely to receive a prescription than enrollees with the lowest deductible of CHF 300 (adjusted $\mathrm{OR}=0.29,95 \% \mathrm{Cl} 0.24$ to 0.35 ).

Individuals with at least one prescription had a higher probability of hospitalisation for trauma $(0 \mathrm{R}=1.31,95 \% \mathrm{Cl}$ 1.20 to 1.1.44), and $70 \%$ higher health care expenditures $(\beta=0.72,95 \% \mathrm{Cl} 0.67$ to 0.77 ). Enrollees in canton Valais were three times more likely to receive a prescription compared to enrollees from canton Aargau ( $\mathrm{OR}=2.84$, 95\% 2.51 to 3.21 ).

Conclusions The proportion of older adults with at least one benzodiazepine prescription is high, as found in the data of one large Swiss health insurance company. These enrollees are more likely to be hospitalised for trauma and have higher healthcare expenditures. Important differences in prescription prevalence across cantons were observed, suggesting potential overuse. Further research is needed to understand the drivers of variation, prescription patterns across providers, and trends over time.
Strengths and limitations of this study

- We analysed a large administrative dataset with detailed patient-level information to provide recent evidence on benzodiazepine prescription in older adults in Switzerland.

- The Swiss context with its decentralised system but homogeneous benefit package offers an opportunity to study regional variation that can shed light on cultural differences in healthcare use.

- We restricted our analysis to the cantons in which direct dispensing by physicians is not allowed; our sample is therefore not representative of all Switzerland.

- By relying on claims data, we have only limited diagnostic information at the individual level and we were therefore unable to identify the reason for benzodiazepine prescriptions.

- We only investigate association between prescription, hospitalisations and costs, and are not able to make any causal claim.

\section{INTRODUCTION}

Benzodiazepines are among the most prescribed psychotropic drugs in high-income countries, widely used for treating anxiety and sleep disorders. Estimates of adult benzodiazepine consumption ( $\geq 18$ years) range from $5 \%$ in the USA to over $16 \%$ in some European countries. ${ }^{12}$ There are growing concerns about the potentially inappropriate use of benzodiazepines, particularly when used for a long period of time. ${ }^{34}$ Studies have found an increase in benzodiazepine prescription with age in both men and women and a positive association with health-related factors such as depression and chronic disease. ${ }^{156}$ Benzodiazepines have been ranked among the most misused drugs, particularly for dependence. ${ }^{7}$ Moreover, guidelines discourage prolonged use of benzodiazepines especially among older people due to severity of adverse effects, particularly those associated with the central nervous system. ${ }^{89}$ Indeed, when used for long 
periods, benzodiazepines may lead to dependency, traumatic falls and fracture, ${ }^{1011}$ hospitalisation and death, ${ }^{12-14}$ leading to increased healthcare costs. ${ }^{81516}$

In 2019, the American Geriatrics Society ${ }^{9}$ published an update of the Beers Criteria to guide prescription in the elderly population. ${ }^{17}$ It recommends avoiding the use of benzodiazepines in elderly patients due to increased sensitivity to these drugs and decreased metabolic rate of long-acting agents. Moreover, use for longer than 4 weeks may be potentially problematic. ${ }^{18}$ Despite the lack of evidence supporting their use beyond short periods, benzodiazepines are often prescribed for longer periods than recommended, particularly among those aged $\geq 65 .^{19}$

In Switzerland, the Choosing Wisely Switzerland ('smarter medicine') top-5 list of low-value interventions for geriatrics includes benzodiazepines (https:// www.smartermedicine.ch) and makes the following recommendation: "Don't use benzodiazepines or other sedative-hypnotics in older adults as first choice for insomnia, agitation or delirium and avoid prescription at discharge" ${ }^{20}$ Use of benzodiazepines is, however, recommended for alcohol withdrawal symptoms/delirium tremens or severe generalised anxiety disorder unresponsive to other therapies. Although concern exists regarding potential overuse, limited information is available regarding patterns of use and its impact in older adults. For instance, a study conducted in 2007 including 520000 participants from the general adult population found that $9.1 \%$ received at least one benzodiazepine prescription within a period of 6 months. ${ }^{21}$

In this study, we use routine health insurance claims data to measure the prevalence of benzodiazepine prescription among individuals aged $\geq 65$ in Switzerland. We further assess patterns of benzodiazepine prescription (eg, number of prescriptions, defined daily dose (DDD)), determinants of prescription, association with hospitalisation and healthcare costs. In addition, we study differences in the prevalence of prescription across cantons to assess potential unwarranted variation and identify regions in need of concerted deprescribing efforts.

\section{METHODS \\ Setting}

Switzerland is a confederation of 26 cantons (states) with a total population of 8.4 million inhabitants. There are four official languages: German (63\%), French (22.7\%), Italian $(8.1 \%)$ and Romansch $(0.5 \%)$. While the Swiss healthcare system performs well in international comparisons, ${ }^{22} 23$ it is also one of the most expensive in the world. The regulation and organisation of healthcare takes place at the three main political levels, that is, central government, cantons and municipalities, with cantons playing a central role in delivery and financing of healthcare services. ${ }^{24}$ This gives rise to disparate cantonal health systems under the umbrella of a common central regulation. Health insurance is mandatory and covers illness, maternity and accidents for all insured individuals who are free to choose among registered health insurance companies that offer the same benefit package. The standard plan offers freedom of provider choice and direct access to secondary care. Enrollees can choose their deductible level (options range from CHF 300 to 2500) and, in return for a lower premium, they can choose alternative healthcare plans (HCPs), with either a general practitioner (GP) or a medical call centre as the first point of contact. ${ }^{25}$ Gatekeeping plans require enrollees to see a GP for referral to specialists, and managed care plans typically restrict access to a list of providers. Premiums are not risk-rated but can vary significantly across regions. Participation of households to healthcare expenditures is important and includes deductibles, co-payments and out-of-pocket expenses, giving rise to a particularly regressive financing system. ${ }^{26}$

\section{Study design and participants}

We conducted a cross-sectional analysis of claims data to study benzodiazepine prescriptions in enrollees aged $\geq 65$ in 2017. We restricted our analysis to the nine Swiss cantons (ie, Aargau, Basel, Freiburg, Geneva, Jura, Neuchatel, Ticino, Vaud and Valais) in which direct medication dispensing by physicians is not allowed, as such prescriptions may not be captured with enough accuracy in the data.

\section{Data sources}

We obtained data from Groupe Mutuel, which is one of the largest health insurance companies in Switzerland, covering some 981160 individuals with mandatory health insurance in 2019. The database provides information on demographic characteristics of enrollees including age, sex and canton of residence, as well as information on insurance plan (deductible level and type of contract (types of contract include basic option, gatekeeping, telephone-based gatekeeping, as well as managed care $(\mathrm{HMO})))$. In addition, the data include information on hospitalisations with the associated diagnosis-related group (DRG), total costs covered by mandatory health insurance, comorbidities ${ }^{\mathrm{i}}$ derived from medication use, ${ }^{27}$ drug prescription information including anonymous prescriber identifier, Anatomical Therapeutic Chemical (ATC) classification system codes and a more detailed Swiss classification code (ie, Pharmacode), number of packs and prescription date. The following ATC codes were used to identify benzodiazepine prescriptions : N05BA and N05CD. We identified two types of hospitalisations using Swiss DRG codes: (1) those potentially related

\footnotetext{
${ }^{\mathrm{i} A t t e n t i o n}$ deficit hyperactivity disorder (ADHD), asthma, autoimmune diseases, cystic fibrosis/pancreatic enzyme, high cholesterol, chronic obstructive pulmonary disease (COPD)/ severe asthma, Crohn's disease/ulcerative colitis, depression, diabetes, type 2 diabetes, epilepsy, glaucoma, heart disease, HIV/AIDS, hormone-sensitive cancer, hypertension, cancer, kidney disease, brain or spinal cord diseases, neuropathic pain, Parkinson's disease, psychosis, Alzheimer, and addiction, rheumatism, thyroid disease, transplantation
} 
to benzodiazepine use, that is, trauma-related (online supplementary file 1), and (2) all other hospitalisations.

\section{Statistical analysis}

We first described participants' characteristics including demographics (ie, age categorised into four main groups: $65-69,70-74,75-80$ and $>80$ years, sex, canton of residence) and insurance details (deductible and plan type), and analysed differences in characteristics between those with and without any benzodiazepine prescription. We also analysed how the prevalence of prescription vary by age and canton. Intensity of potential benzodiazepine use among individuals with at least one prescription was captured using number of benzodiazepine prescriptions and total number of DDD. We also produced an estimate of the treatment duration, and computed mean daily dose by combining information on prescription dates and DDDs. ${ }^{28}$ Finally, we analysed (1) the determinants of any benzodiazepine prescription and (2) the association between any prescription and the probability of trauma-related hospitalisations using logistic regression, as well as (3) the association between any prescription and total healthcare expenditures using a linear regression with log-transformed costs. ${ }^{29}$ This specification was preferred to two-part or zero-inflated models as we have a highly skewed distribution of costs, but only a small proportion of enrollees with zero cost. Control variables included age, canton of residence, deductible level, type of contract, total number of non-trauma hospitalisations as a proxy for health status and comorbidities. In addition to ORs and regression coefficients, we report predicted outcomes (ie, hospitalisation rate and healthcare expenditures) to reflect the contribution of each value of each covariate to the outcomes of interest, all else being equal.

Data management and analysis were conducted using Stata V.15.1 (StataCorp LP, College Station, Texas, USA).

\section{Patient and public involvement}

Patients and the public were not involved in the design or

planning of the study.

\section{RESULTS}

\section{Descriptive statistics}

Our study population consisted of 69005 individuals aged 65 and older (table 1). The mean age for all enrollees was 75.1 years and over half were women $(55 \%)$. The majority of participants $(57 \%)$ had a basic health insurance plan without a specific model and chose the lowest deductible level of CHF 300 (55\%). Among all included individuals, $20.4 \%$ had at least one benzodiazepine prescription during the study period.

The prevalence of any benzodiazepine prescription increased with age and was highest (25.8\%) among age group 80 and older. Women had higher (25.1\%) prevalence compared with men $(14.6 \%)$. Study participants with a basic health insurance $(22.1 \%)$ and those with the lowest deductible level $(23.6 \%)$ had higher prevalence of benzodiazepine prescription. Overall, over half of the study participants $(55.7 \%)$ had no comorbidity and about a third had one comorbidity $(32 \%)$. The highest prevalence of benzodiazepine prescription was observed among those with five or more comorbidities (44\%).

Figure 1 shows variation of prescription prevalence by age and canton of residence. In all cantons, except in canton of Fribourg where prevalence dropped among older enrollees, prevalence increased steadily with age to reach about $30 \%$ for the oldest age group in some cantons. We also observe important variation between cantons, with prevalence varying by a factor of 2 between the highest and the lowest prescribing cantons. Of note, the two lowest prescribing cantons are in the Germanspeaking part of the country, whereas the other cantons are in the French-speaking or Italian-speaking regions.

A total of 75130 benzodiazepine prescriptions were filled in 2017. The most commonly prescribed products were lorazepam $(39.9 \%)$, oxazepam $(16.4 \%)$ and bromazepam $(13.1 \%$ ) (table 2 ). The majority of individuals with at least one prescription received intermediate-acting benzodiazepine agents $(67.7 \%)$, followed by long-acting benzodiazepines $(25 \%)$ and only a small proportion $(7.4 \%)$ received short-acting benzodiazepines.

The mean number of prescriptions among those with at least one prescription was 4.9 (SD 5.4, median 4), and the mean DDD was 111.23 (SD 145.4, median 60). About onethird of users received at least five prescriptions during the year and $40 \%$ were prescribed the equivalent of 90 DDD or more. More importantly, the estimated treatment duration is above 15 days for $80 \%$ of users, suggesting high prevalence of long-term use. By combining information on prescription dates and DDD, we calculated a mean daily dose of 0.85 (SD 1.65, median 0.70 ).

\section{Determinants of benzodiazepine prescription}

Logistic regression results are presented in table 1 . The probability of any benzodiazepine prescription increased with age. For example, the adjusted OR was 1.29 (95\% CI 1.22 to 1.36$)$ for enrollees aged $75-80$ and 1.41 (95\% CI 1.34 to 1.49 ) for those aged 80 and older (ref: 65-69). Men were $50 \%$ less likely to be prescribed benzodiazepines as women (adjusted $\mathrm{OR}=0.53,95 \% \mathrm{Cl} 0.51$ to 0.55 ). The model also revealed significant differences in prescribing patterns between cantons, with for instance prevalence of prescription being nearly three times higher in canton Valais than in the reference canton of Aargau ( $\mathrm{OR}=2.84$, 95\% CI 2.51 to 3.21 ).

We observed an association between deductible level and benzodiazepine prescription. Enrollees with higher deductibles were less likely to receive a prescription. For instance, enrollees with the highest deductible level of CHF 2500 were $70 \%$ less likely to receive a prescription than enrollees with a deductible of CHF 300 ( $\mathrm{OR}=0.29$, $95 \%$ CI 0.24 to 0.35 ). Having chronic conditions was associated with benzodiazepine prescription. For example, among individuals with one chronic condition, the OR 
Table 1 Sample characteristics, $2017(n=69005)$

\begin{tabular}{lllll} 
N (\%) & $\begin{array}{l}\text { \% with any } \\
\text { benzodiazepine } \\
\text { prescription }\end{array}$ & $\begin{array}{l}\text { Adjusted \% with } \\
\text { any benzodiazepine } \\
\text { prescription* }\end{array}$ & $\begin{array}{l}\text { Unadjusted OR } \\
(95 \% \mathrm{Cl})\end{array}$ & $\begin{array}{l}\text { Adjusted OR } \\
(95 \% \mathrm{Cl})\end{array}$ \\
\hline
\end{tabular}

\begin{tabular}{|c|c|c|c|c|c|}
\hline \multicolumn{6}{|l|}{ Age groups } \\
\hline $65-69$ & $19553(28.3)$ & 15.9 & 20.4 & - & - \\
\hline $70-74$ & $17773(25.8)$ & 18.4 & 21.4 & 1.18 (1.12 to 1.25$)$ & 1.08 (1.02 to 1.15$)$ \\
\hline $75-80$ & $14820(21.5)$ & 22.5 & 23.6 & 1.53 (1.45 to 1.62$)$ & 1.29 (1.22 to 1.36$)$ \\
\hline $80+$ & $16859(24.4)$ & 25.8 & 24.5 & 1.83 (1.74 to 1.93$)$ & 1.41 (1.34 to 1.49 ) \\
\hline \multicolumn{6}{|l|}{ Sex } \\
\hline Female & $38259(55.4)$ & 25.1 & 24.5 & - & - \\
\hline Male & $30746(44.6)$ & 14.6 & 15.1 & 0.51 (0.49 to 0.53 ) & 0.53 (0.51 to 0.55$)$ \\
\hline \multicolumn{6}{|l|}{ Canton } \\
\hline NE & 3594 (5.2) & 24.9 & 23.2 & 3.53 (3.09 to 4.05$)$ & 2.72 (2.37 to 3.12 ) \\
\hline VS & 12159 (17.6) & 24 & 23.9 & 3.37 (2.99 to 3.79 ) & 2.84 (2.51 to 3.21$)$ \\
\hline GE & $12753(18.5)$ & 23.1 & 21.8 & 3.21 (2.85 to 3.61$)$ & 2.50 (2.21 to 2.83 ) \\
\hline JU & $1672(2.4)$ & 22 & 21.7 & 3.00 (2.56 to 3.53 ) & 2.49 (2.11 to 2.93 ) \\
\hline $\mathrm{TI}$ & $3591(5.2)$ & 21.6 & 22.8 & 2.94 (2.56 to 3.37 ) & 2.65 (2.31 to 3.05 ) \\
\hline VD & 23363 (33.9) & 19.4 & 19.2 & 2.57 (2.29 to 2.88 ) & 2.11 (1.88 to 2.39 ) \\
\hline FR & $5742(8.3)$ & 18.2 & 19.4 & 2.38 (2.09 to 2.70$)$ & 2.15 (1.88 to 2.46 ) \\
\hline BS & $2145(3.1)$ & 12.5 & 12.9 & 1.52 (1.28 to 1.80$)$ & 1.29 (1.09 to 1.54$)$ \\
\hline$A G$ & $3986(5.8)$ & 8.6 & 10.4 & - & - \\
\hline \multicolumn{6}{|l|}{ Insurance plan } \\
\hline Basic plan & $39310(57.0)$ & 22.1 & 21.1 & - & - \\
\hline Gatekeeping & $14706(21.3)$ & 19.6 & 20.4 & 0.86 (0.82 to 0.90$)$ & 0.96 (0.91 to 1.01$)$ \\
\hline Phone-based gatekeeping & $8776(12.7)$ & 14.9 & 17.6 & 0.61 (0.58 to 0.65$)$ & 0.79 (0.74 to 0.85$)$ \\
\hline Managed care (HMO) & $6213(9.0)$ & 19.3 & 19.4 & 0.84 (0.79 to 0.90$)$ & 0.89 (0.83 to 0.96$)$ \\
\hline \multicolumn{6}{|l|}{ Deductible (CHF) } \\
\hline 300 & $38037(55.1)$ & 23.6 & 22.3 & - & - \\
\hline 500 & $22415(32.5)$ & 19.7 & 19.5 & $0.79(0.76$ to 0.83$)$ & 0.83 (0.80 to 0.87$)$ \\
\hline 1000 & $2004(2.9)$ & 11.9 & 15 & $0.44(0.38$ to 0.50$)$ & 0.60 (0.52 to 0.69$)$ \\
\hline 1500 & $3667(5.3)$ & 8.6 & 12.4 & 0.31 (0.27 to 0.34$)$ & 0.47 (0.42 to 0.54$)$ \\
\hline 2000 & $395(0.6)$ & 6.6 & 10 & $0.23(0.15$ to 0.34$)$ & 0.37 (0.25 to 0.56$)$ \\
\hline 2500 & $2487(3.6)$ & 5.1 & 8 & $0.17(0.15$ to 0.21$)$ & 0.29 (0.24 to 0.35$)$ \\
\hline \multicolumn{6}{|l|}{ Comorbidities (PCG) } \\
\hline 0 & $38430(55.7)$ & 15.1 & 15.7 & - & - \\
\hline 1 & $22231(32.2)$ & 24.6 & 24 & $1.83(1.76$ to 1.91$)$ & 1.73 (1.66 to 1.80$)$ \\
\hline 2 & $6813(9.9)$ & 32.2 & 29.8 & 2.67 (2.52 to 2.83$)$ & 2.36 (2.22 to 2.50$)$ \\
\hline 3 & $1317(1.9)$ & 38.2 & 34.3 & 3.47 (3.09 to 3.89$)$ & 2.94 (2.61 to 3.30$)$ \\
\hline 4 & $189(0.3)$ & 41.8 & 37.1 & 4.03 (3.02 to 5.39$)$ & 3.35 (2.49 to 4.51$)$ \\
\hline $5+$ & $25(0.0)$ & 44 & 36.6 & 4.41 (2.00 to 9.72$)$ & 3.27 (1.46 to 7.32$)$ \\
\hline Overall & & 20.4 & & & \\
\hline
\end{tabular}

\begin{tabular}{lcl}
\hline Outcomes & Benzodiazepine users $\mathbf{( n = 1 4 0 7 2 )}$ & Non-users $(\mathbf{n}=\mathbf{5 4 9 2 5})$ \\
\hline Healthcare expenditures, mean (SD) & $15573(19040)$ & $9111(14848)$ \\
Hospitalisation (any), N (\%) & $3841(27.3)$ & $9298(16.9)$ \\
Hospitalisation (trauma), N (\%) & $760(5.4)$ & $1925(3.5)$ \\
\hline
\end{tabular}

${ }^{*}$ Adjusted for age, sex, canton, insurance plan, deductible (CHF) and comorbidities.

PCG, pharmaceutical cost group. 


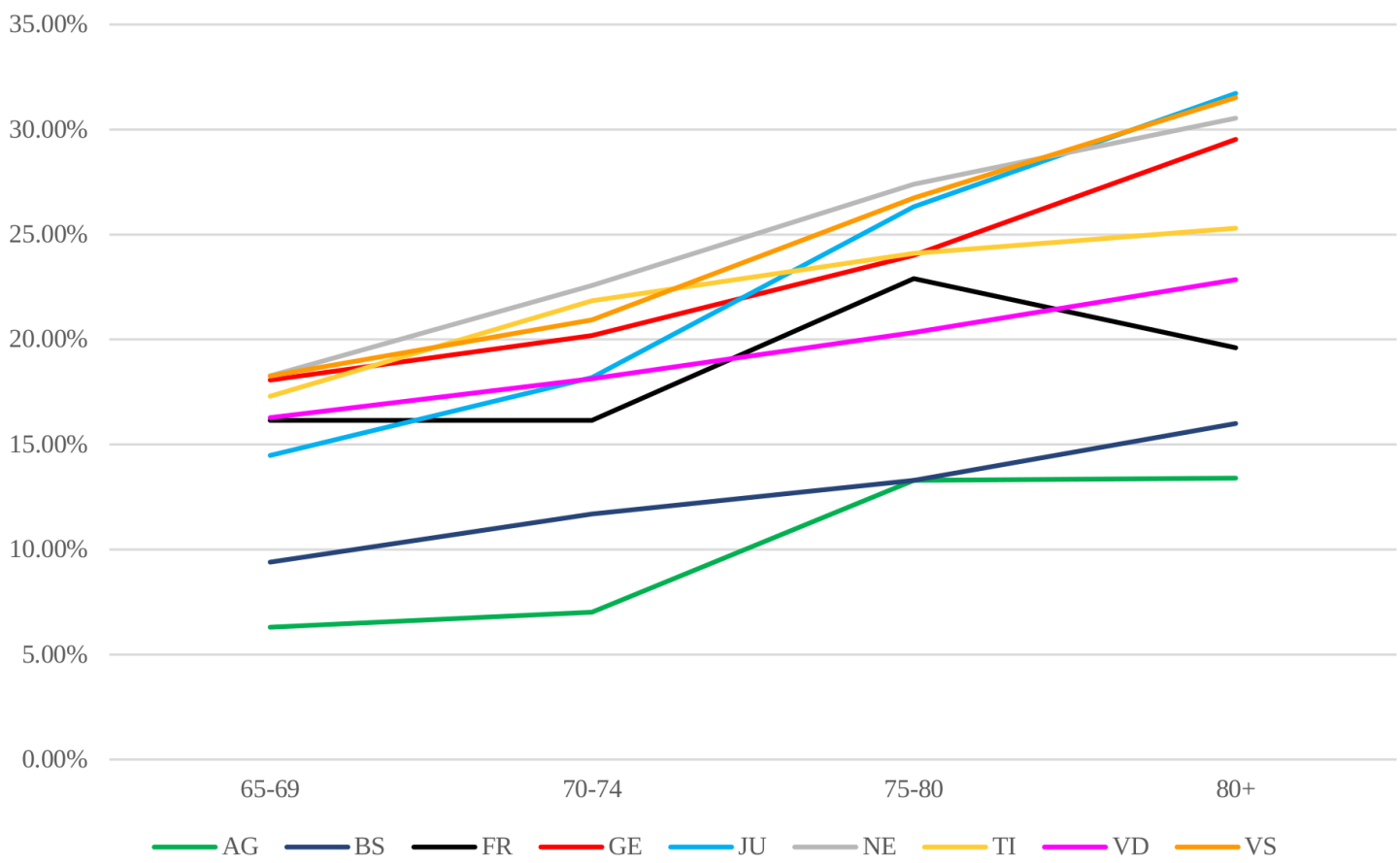

Figure 1 Prescription prevalence by age groups and canton, 2017.

was 1.73 (95\% CI 1.66 to 1.80 ) and increased to 3.27 among those with five or more comorbidities $(95 \% \mathrm{CI}$ 1.46 to 7.32 ).

\section{Association with hospitalisations and healthcare expenditures} Overall, $19 \%$ of individuals had at least one hospital admission during the study period. Individuals with a benzodiazepine prescription were more likely to be hospitalised for any cause $(27.3 \%$ vs $16.9 \%)$ and for trauma $(5.4 \%$ vs $3.5 \%$ ) compared to non-users. Total healthcare expenditures were higher for those with a prescription than for non-users (CHF 15573 vs 9111). Table 3 shows the association between benzodiazepine prescription, hospitalisations and healthcare expenditures. Individuals with any benzodiazepine prescription had higher probability of being hospitalised for trauma (OR=1.31, 95\% CI 1.20 to 1.44) table 3. As expected, hospitalisation rate increased with age and comorbidities. Our models of total healthcare expenditures showed that those with at least one prescription had $70 \%$ higher expenditures compared to non-users $(\beta=0.72,95 \%$ CI 0.67 to 0.77$)$.

\section{DISCUSSION}

In this retrospective analysis of insurance claims data, the proportion of individuals aged 65 years and older with at least one prescription of benzodiazepines in 2017 was about $20 \%$. The prevalence of prescription increased with age and was higher among women. We also found important variation in prescription prevalence across cantons, with prevalence ranging from $16 \%$ to $31 \%$. Having more than one comorbidity and having a lower deductible was associated with a higher probability of benzodiazepine prescription. Finally, we found an association between benzodiazepine prescription, hospitalisation for trauma and healthcare expenditures.

This is one of the first studies investigating benzodiazepine prescription in older adults in Switzerland. A study conducted in the general population ${ }^{21}$ showed a prevalence of benzodiazepine dependence of $16 \%-20 \%$ with many patients $(49.3 \%)$ receiving benzodiazepines on a long-term basis and $8.3 \%$ receiving benzodiazepines in high doses. A recently published Swiss study using claims data found no association between use and the risk of Alzheimer's disease, ${ }^{31}$ contrary to previous evidence. ${ }^{32}$ In other countries the prevalence of benzodiazepine use in the elderly population ranged from $15 \%$ to $31 \% .^{1633-35}$ In our study, about $20 \%$ of enrollees received at least one benzodiazepine prescription in 2017, with two-thirds of them receiving the equivalent of $30 \mathrm{DDD}$ or more, and $80 \%$ with estimated treatment durations longer than 2 weeks. Thus, considering that use is typically not recommended beyond 2-4 weeks of treatment, ${ }^{17} 36$ the prevalence of benzodiazepine overuse among older people in Switzerland is likely to be as high as $16 \%$. This proportion might be twice higher in non-German-speaking cantons, among women over 80 years old and in multimorbid people.

High prevalence of benzodiazepine prescription among older adults appears to be common in many parts of the world. For example, a study in the USA found that $5.2 \%$ of the adult population were benzodiazepine users. ${ }^{1}$ People receiving prescription from a psychiatrist were more likely to be long-term users and this tendency increased with age (33\% in younger adults and $53.5 \%$ in older adults). In Australia, $16 \%$ of the adults aged 65 years and older had at least one benzodiazepine prescription 
Table 2 Details on benzodiazepine prescriptions, 2017

$\%$ of all benzodiazepine prescriptions

\begin{tabular}{|c|c|c|c|c|}
\hline \multicolumn{5}{|l|}{$\begin{array}{l}\text { Panel A: prescribed } \\
\text { benzodiazepines }(n=75130)\end{array}$} \\
\hline \multicolumn{5}{|l|}{ Anxiolitics (N05BA) } \\
\hline \multicolumn{5}{|l|}{ Intermediate acting } \\
\hline \multicolumn{2}{|l|}{ Lorazepam } & 29945 & 39.9 & \\
\hline \multicolumn{2}{|l|}{ Oxazepam } & 12298 & 16.4 & \\
\hline \multicolumn{2}{|l|}{ Alprazolam } & 5843 & 7.8 & \\
\hline \multicolumn{2}{|c|}{ Lorazepam+Diphenhydramine } & 1557 & 2.1 & \\
\hline \multicolumn{5}{|l|}{ Long acting } \\
\hline \multicolumn{2}{|l|}{ Bromazepam } & 9840 & 13.1 & \\
\hline \multicolumn{2}{|l|}{ Clorazepate } & 3782 & 5.0 & \\
\hline \multicolumn{2}{|l|}{ Prazepam } & 1122 & 1.5 & \\
\hline \multicolumn{2}{|c|}{$\begin{array}{l}\text { Others (ie, diazepam, clobazam, } \\
\text { kétazolam) }\end{array}$} & 456 & 0.6 & \\
\hline \multicolumn{5}{|c|}{ Hypnotics and sedatives (N05CD) } \\
\hline \multicolumn{5}{|l|}{ Short acting } \\
\hline \multicolumn{2}{|l|}{ Midazolam } & 3524 & 4.7 & \\
\hline \multicolumn{2}{|l|}{ Triazolam } & 2039 & 2.7 & \\
\hline \multicolumn{5}{|l|}{ Intermediate acting } \\
\hline \multicolumn{2}{|l|}{ Lormatezepam } & 755 & 1.0 & \\
\hline \multicolumn{2}{|l|}{ Temazepam } & 366 & 0.5 & \\
\hline \multicolumn{5}{|l|}{ Long acting } \\
\hline \multicolumn{2}{|l|}{ Flurazepam } & 2461 & 3.3 & \\
\hline \multicolumn{2}{|l|}{ Flunitrazepam } & 838 & 1.1 & \\
\hline \multicolumn{2}{|l|}{ Nitrazepam } & 284 & 0.4 & \\
\hline & Mean & SD & Median & IQR \\
\hline \multicolumn{5}{|l|}{$\begin{array}{l}\text { Panel B: prescriptions } \\
\text { among users }(n=14072)\end{array}$} \\
\hline $\begin{array}{l}\text { No. of benzodiazepine } \\
\text { prescriptions }\end{array}$ & 4.94 & 5.43 & 4 & 6 \\
\hline DDD & 111.23 & 145.40 & 60 & 128 \\
\hline Mean daily dose & 0.85 & 1.65 & 0.70 & 0.62 \\
\hline No. of different prescribers & 1.25 & 0.57 & 1 & 0 \\
\hline $\begin{array}{l}\text { No. of different drugs } \\
\text { prescribed (any type) }\end{array}$ & 10.2 & 7.2 & 9 & 9 \\
\hline
\end{tabular}

\begin{tabular}{lcc}
\hline & $\mathbf{N}$ & $\%$ \\
\hline No. of benzodiazepine prescriptions & & \\
\hline 1 & 3839 & 27.3 \\
\hline $2-5$ & 5278 & 37.5 \\
\hline $5-10$ & 3427 & 24.4 \\
\hline $10+$ & 1528 & 10.9 \\
\hline DDD & & \\
\hline $0-30$ & 5046 & 35.9 \\
\hline $30-90$ & 3371 & 24.0 \\
\hline $90-180$ & 3142 & 22.3 \\
\hline $180-360$ & 1713 & 12.2 \\
\hline $360+$ & 800 & 5.7 \\
\hline Estimated treatment duration (days) & & \\
\hline
\end{tabular}

Continued

\section{Table 2 Continued}

\begin{tabular}{lll} 
& $\mathbf{N}$ & $\%$ \\
\hline $0-15$ & 2936 & 20.1 \\
$15-90$ & 2095 & 14.9 \\
$90-180$ & 2182 & 15.5 \\
$180-270$ & 2440 & 17.3 \\
$270+$ & 4419 & 31.4 \\
Mean daily dose & & \\
$0-0.5$ & 5317 & 37.8 \\
$0.5-1$ & 6893 & 50.0 \\
$1-2$ & 1429 & 10.2 \\
$2+$ & 433 & 3.1 \\
\hline
\end{tabular}

${ }^{*}$ Total number of prescriptions of different therapeutic/pharmacological subgroups (ATC 4-digit). DDD, defined daily dose.

with higher prevalence in women and those aged 65 and older. ${ }^{34}$ A recent German retrospective study including over 32000 older people showed that the proportion of patients receiving benzodiazepine therapy for over 6 months was approximately $15 \%-20 \%$. Similar to our findings, use of benzodiazepines was more frequent in older people, patients treated in neuropsychiatric practices, and people diagnosed with dementia, sleep disorders or depression. ${ }^{6}$

The fact that over three quarters of individuals with at least one benzodiazepine prescription are long-term users reflects the challenge of discontinuing such treatment. Research suggests that the main barriers to reducing or stopping prescription of psychotropic drugs in clinical practices are patient perceived difficulty to stop the medication and lack of alternative therapies such as cognitive behavioural therapy. ${ }^{37}$ Moreover, healthcare providers may not recommend discontinuing benzodiazepines due to concerns related with withdrawal symptoms, which may occur in up to $50 \%$ of patients. ${ }^{38}$ Our findings are consistent with previous research ${ }^{33} 3940$ showing higher prevalence of prescription among women. The increase of benzodiazepine prescription with the number of chronic conditions can be partly explained by poorer quality of sleep and more prevalent anxiety in this group. It is also possible that more frequent physician visits increase the risk of initiating hypnotic treatment.

We found higher rates of trauma-related hospital admissions and higher healthcare expenditures in individuals with at least one benzodiazepine prescription than in non-users. Previous research has consistently reported that benzodiazepine use is associated with significant increase in risk of falls. ${ }^{4-43}$ A meta-analysis reported up to $50 \%$ increase in risk of falls among benzodiazepine users. ${ }^{44}$ Fall-related injuries are one of the most expensive medical conditions and may have major economic consequences on healthcare systems. ${ }^{45}$ Research from the USA suggests that the average cost for fall injury is over $\$ 30000$ and increases with age. ${ }^{46}$ 
Table 3 Association with hospitalisation and costs

\section{Outcome: any hospitalisation for trauma}

Logistic regression

\section{Outcomes: In(health expenditure)} OLS ( $\beta$ reported)*

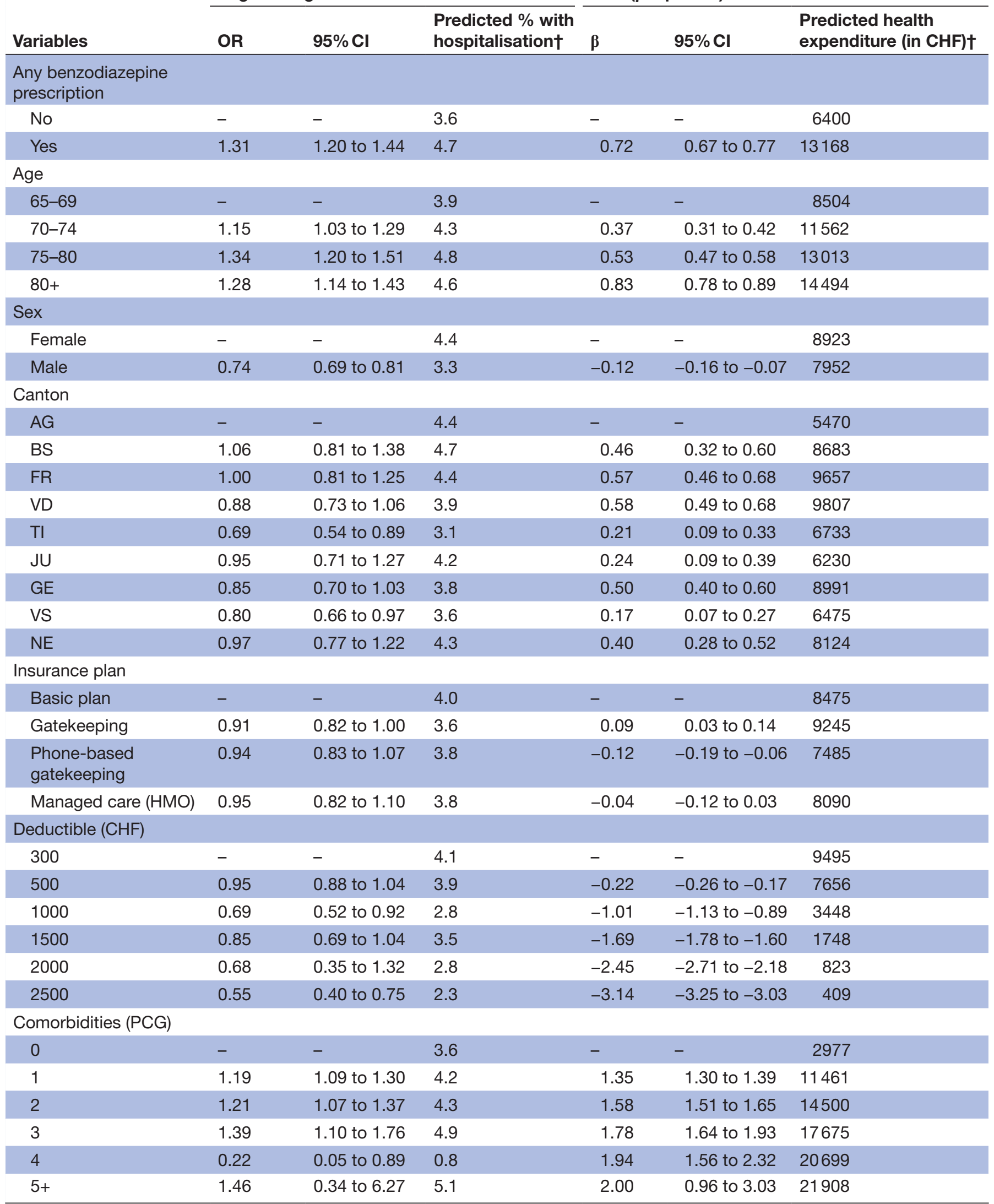

Continued 
Outcome: any hospitalisation for trauma Logistic regression

\section{Outcomes: In(health expenditure)} OLS ( $\beta$ reported)*

\begin{tabular}{|c|c|c|c|c|c|c|}
\hline \multirow[b]{2}{*}{ Variables } & & \\
\hline & OR & $95 \% \mathrm{Cl}$ & $\begin{array}{l}\text { Predicted \% with } \\
\text { hospitalisation } \dagger\end{array}$ & $\boldsymbol{\beta}$ & $95 \% \mathrm{Cl}$ & $\begin{array}{l}\text { Predicted health } \\
\text { expenditure (in CHF)† }\end{array}$ \\
\hline \multicolumn{7}{|c|}{$\begin{array}{l}\text { Total number of hospital } \\
\text { admissions (non-trauma) }\end{array}$} \\
\hline 0 & - & - & 3.4 & - & - & 3704 \\
\hline 1 & 1.69 & 1.52 to 1.88 & 5.7 & 1.69 & 1.63 to 1.76 & 20131 \\
\hline
\end{tabular}

*Semielasticity.

†Obtained by predicting the outcome for each value of each covariate, all else being equal.

PCG, pharmaceutical cost group.

Finally, we observed a large variation across cantons in the prevalence of benzodiazepine prescription. The variation could be due to several factors including patient and provider characteristics, as well as factors related to the organisation of healthcare (eg, guidelines, incentives, different local practice patterns). Large differences in healthcare utilisation across the three language regions (French, German and Italian) have been reported in several Swiss studies, which might reflect cultural differences. ${ }^{47-49}$ In particular, substantial cantonal variation in prescriptions for other types of drugs has been reported in previous Swiss studies, for example, in Wertli et al $(2017)^{50}$ who found pronounced geographical differences in prescription of pain medications.

\section{Strengths and limitations}

This study has several strengths. First, select data from individuals were available with detailed patient-level information to provide recent evidence on benzodiazepine prescription in older people in Switzerland. Such data are not readily available in the country and previous studies have often relied on survey data. ${ }^{21} 5152$ In addition, the Swiss context with its decentralised system but homogeneous benefit package offers an opportunity to study regional variation that can shed light on cultural differences in healthcare use.

Our study has also several limitations. First, we restricted our analysis to the cantons in which direct dispensing by physicians is not allowed; our sample is therefore not representative of all Switzerland. In addition, as we are relying on claims data, we have only limited diagnostic information at the individual level and we were therefore unable to identify the reason for prescription, and we are only able to analyse prescriptions filled and not actual medication use. Also, our study is likely to underestimate prescription prevalence as a share of prescriptions is likely to be paid out-of-pocket and therefore not recorded in claims data; our findings on the negative association between deductible level and benzodiazepines prescription could partly reflect this. Also, while our data capture information on the number of providers, we were not able to identify the type of prescribing physician which has been previously identified as an important determinant of benzodiazepine prescription..$^{53}$ Also, as benzodiazepine misuse at older ages may reflect misuse and consequent habituation at younger ages, focusing on the population aged 65 and older is a limitation. Future studies should examine patterns and initiation of problematic use in different age groups, and persistence of misuse over time. Finally, we only investigate association between prescription, hospitalisation and costs and are not able to make any causal claim.

\section{Implications for clinicians and policy makers}

Despite these limitations, our study has important implications for patients, healthcare providers and policy makers. Our results indicate that benzodiazepine overuse among older adults is likely to be a public health issue in Switzerland. It is thus necessary to analyse the causes and the consequences of this phenomenon. Is it driven by patient demand or by physician supply, with a minority of doctors initiating such treatments? Potential explanations of excessive prescription by doctors include inaccurate appreciation of the risk-benefit trade-off of the medication, poor knowledge of alternative treatment options or consultation time constraints while facing complex psychosocial problems. ${ }^{545}$

In this context, the development of clearer prescription guidelines, accompanied with improved monitoring of use, might help curb prescription rates. As overuse may be driven by variation in prescribing practice, future interventions could target prescribers in cantons with highest prescribing rates. Results shown in this study could also be used to set a national benchmark. For instance, authorities could aim for a target of use in adults age 65 and older, which would be realistic and reflect what is achievable in some cantons (eg, $<10 \%$ in use). Future research should also look into why some cantons are able to achieve such low prevalence compared with others. It will also be important to better understand why multimorbid 
patients consume benzodiazepines more frequently and whether the observed associations between benzodiazepine prescription, hospitalisation rates and healthcare expenditures reflect causality.

Our findings may be generalised to other developed countries that face similar challenges in their healthcare system (eg, ageing population and increasing healthcare costs).

\section{CONCLUSIONS}

We found evidence of high prevalence of prescription in this population, in particular in non-German-speaking cantons, women over 80 years old and in people with comorbidities. Future studies could identify patterns of prescription across provider type and trends over time. The use of benzodiazepines is high and is associated with trauma and healthcare expenditures, with variability across cantons, suggesting regional/prescriber directed interventions could address overuse. Further efforts are also needed to examine causality using longitudinal data.

\section{Twitter Xhyljeta Luta @xluta}

Acknowledgements We are grateful to Groupe Mutuel for providing us with the data used in the study and other relevant information. We would also like to thank the reviewers for their helpful comments and suggestions.

Contributors JM was the principal investigator on the project and led the analyses. CB actively collaborated on data preparation, description, analysis and interpretation. $\mathrm{ML}$ and $\mathrm{CB}$ were involved in data management. $\mathrm{XL}$ and $\mathrm{JM}$ drafted the manuscript. AD, YE, M-ALP and PM-V provided input in the analysis phase. All authors provided critical feedback and approved the final version of the manuscript.

Funding This work was supported by the Swiss Medical Board (www.medicalboard.ch).

Competing interests None declared.

Patient consent for publication Not required.

Ethics approval In our analysis we used routinely collected anonymous data; therefore, ethical approval was not required according to the Swiss law for research on humans. ${ }^{30}$

Provenance and peer review Not commissioned; externally peer reviewed.

Data availability statement The insurance claims data cannot be made publicly available.

Open access This is an open access article distributed in accordance with the Creative Commons Attribution Non Commercial (CC BY-NC 4.0) license, which permits others to distribute, remix, adapt, build upon this work non-commercially, and license their derivative works on different terms, provided the original work is properly cited, appropriate credit is given, any changes made indicated, and the use is non-commercial. See: http://creativecommons.org/licenses/by-nc/4.0/.

\section{ORCID iDs}

Xhyljeta Luta http://orcid.org/0000-0002-5716-4693

Marie-Annick Le Pogam http://orcid.org/0000-0003-1672-3644

Joachim Marti http://orcid.org/0000-0001-5763-3704

\section{REFERENCES}

1 Olfson M, King M, Schoenbaum M. Benzodiazepine use in the United States. JAMA Psychiatry 2015;72:136-42.

2 Huerta C, Abbing-Karahagopian V, Requena G, et al. Exposure to benzodiazepines (anxiolytics, hypnotics and related drugs) in seven European electronic healthcare databases: a cross-national descriptive study from the PROTECT-EU project. Pharmacoepidemiol Drug Saf 2016;25(Suppl 1):56-65.
3 Schmitz A. Benzodiazepine use, misuse, and abuse: a review. Ment Health Clin 2016;6:120-6.

4 Baldwin DS, Aitchison K, Bateson A, et al. Benzodiazepines: risks and benefits. A reconsideration. J Psychopharmacol 2013;27:967-71.

5 Mokhar A, Tillenburg N, Dirmaier J, et al. Potentially inappropriate use of benzodiazepines and z-drugs in the older population-analysis of associations between long-term use and patient-related factors. PeerJ 2018;6:e4614.

6 Jacob L, Rapp MA, Kostev K. Long-Term use of benzodiazepines in older patients in Germany: a retrospective analysis. Ther Adv Psychopharmacol 2017;7:191-200.

7 Nutt D, King LA, Saulsbury W, et al. Development of a rational scale to assess the harm of drugs of potential misuse. Lancet 2007;369:1047-53.

8 Fick DM, Cooper JW, Wade WE, et al. Updating the beers criteria for potentially inappropriate medication use in older adults: results of a US consensus panel of experts. Arch Intern Med 2003;163:2716-24.

9 By the 2019 American Geriatrics Society Beers Criteria $₫$ Update Expert Panel. American geriatrics Society 2019 updated AGS beers Criteria ${ }^{\circledR}$ for potentially inappropriate medication use in older adults. J Am Geriatr Soc 2019;67:674-94.

10 van der Hooft CS, Schoofs MWCJ, Ziere G, et al. Inappropriate benzodiazepine use in older adults and the risk of fracture. $\mathrm{Br} \mathrm{J}$ Clin Pharmacol 2008;66:276-82.

11 Finkle WD, Der JS, Greenland S, et al. Risk of fractures requiring hospitalization after an initial prescription for zolpidem, alprazolam, lorazepam, or diazepam in older adults. J Am Geriatr Soc 2011;59:1883-90.

12 Peel NM. Epidemiology of falls in older age. Can J Aging/ La Revue canadienne du vieillissement 2011;30:7-19.

13 Ballokova A, Peel NM, Fialová D, et al. Use of benzodiazepines and association with falls in older people admitted to hospital: a prospective cohort study. Drugs Aging 2014;31:299-310.

14 Hampton LM, Daubresse M, Chang H-Y, et al. Emergency department visits by adults for psychiatric medication adverse events. JAMA Psychiatry 2014;71:1006-14.

15 Panneman MJM, Goettsch WG, Kramarz P, et al. The costs of benzodiazepine-associated hospital-treated fall injuries in the EU: a Pharmo study. Drugs Aging 2003;20:833-9.

16 Dionne P-A, Vasiliadis H-M, Latimer E, et al. Economic impact of inappropriate benzodiazepine prescribing and related drug interactions among elderly persons. Psychiatr Serv 2013;64:331-8.

17 By the American Geriatrics Society 2015 Beers Criteria Update Expert Panel. American geriatrics Society 2015 updated beers criteria for potentially inappropriate medication use in older adults. $J$ Am Geriatr Soc 2015;63:2227-46.

18 Lader M. Benzodiazepines revisited--will we ever learn? Addiction 2011;106:2086-109.

19 Gerlach LB, Maust DT, Leong SH, et al. Factors associated with long-term benzodiazepine use among older adults. JAMA Intern Med 2018;178:1560-2.

20 Hui D. Benzodiazepines for agitation in patients with delirium: selecting the right patient, right time, and right indication. Curr Opin Support Palliat Care 2018;12:489-94.

21 Petitjean S, Ladewig D, Meier CR, et al. Benzodiazepine prescribing to the Swiss adult population: results from a national survey of community pharmacies. Int Clin Psychopharmacol 2007;22:292-8.

22 De Pietro C, Camenzind P, Sturny I, et al. Switzerland: health system review. Health Syst Transit 2015;17:1-288. xix.

23 OECD, World Health Organization. OECD reviews of health systems: Switzerland 2011.

24 Biller-Andorno N, Zeltner T. Individual responsibility and community solidarity--the Swiss health care system. N Engl J Med 2015;373:2193-7.

25 Keizer E, Huibers L, Bondo Christensen M, et al. Impact of alternative healthcare plans on out-of-hours help-seeking intentions in Switzerland. Swiss Med Wkly 2018;148:w14686.

26 Crivelli L, Salari P. The inequity of the Swiss health care system financing from a federal state perspective. Int $J$ Equity Health 2014;13:17.

27 Huber CA, Szucs TD, Rapold R, et al. Identifying patients with chronic conditions using pharmacy data in Switzerland: an updated mapping approach to the classification of medications. BMC Public Health 2013;13:1030.

28 Manthey L, van Veen T, Giltay EJ, et al. Correlates of (inappropriate) benzodiazepine use: the Netherlands study of depression and anxiety (NESDA). Br J Clin Pharmacol 2011;71:263-72.

29 Deb P, Norton EC. Modeling health care expenditures and use. Annu Rev Public Health 2018;39:489-505.

30 Junod V, Elger B. Retrospective research: what are the ethical and legal requirements? Swiss Med Wkly 2010;140:w13041. 
31 Biétry FA, Pfeil AM, Reich O, et al. Benzodiazepine use and risk of developing Alzheimer's disease: a case-control study based on Swiss claims data. CNS Drugs 2017;31:245-51.

32 Billioti de Gage S, Moride Y, Ducruet T, et al. Benzodiazepine use and risk of Alzheimer's disease: case-control study. BMJ 2014;349:g5205.

33 Davies SJC, Jacob B, Rudoler D, et al. Benzodiazepine prescription in Ontario residents aged 65 and over: a population-based study from 1998 to 2013. Ther Adv Psychopharmacol 2018;8:99-114.

34 Windle A, Elliot E, Duszynski K, et al. Benzodiazepine prescribing in elderly Australian general practice patients. Aust N Z J Public Health 2007;31:379-81.

35 Johnson CF, Frei C, Downes N, et al. Benzodiazepine and z-hypnotic prescribing for older people in primary care: a cross-sectional population-based study. Br J Gen Pract 2016;66:e410-5.

36 Ashton $\mathrm{H}$. The diagnosis and management of benzodiazepine dependence. Curr Opin Psychiatry 2005;18:249-55.

37 Lasserre A, Younès N, Blanchon T, et al. Psychotropic drug use among older people in general practice: discrepancies between opinion and practice. Br J Gen Pract 2010;60:e156-62.

38 Cook JM, Biyanova T, Masci C, et al. Older patient perspectives on long-term anxiolytic benzodiazepine use and discontinuation: a qualitative study. J Gen Intern Med 2007;22:1094-100.

39 Fulone I, Silva MT, Lopes LC. Long-term benzodiazepine use in patients taking antidepressants in a public health setting in Brazil: a cross-sectional study. BMJ Open 2018;8:e018956.

40 Tournier M, Pariente A, Bégaud B, et al. [Use and misuse of benzodiazepines out of France]. Presse Med 2018;47:882-5.

41 Hill KD, Wee R. Psychotropic drug-induced falls in older people: a review of interventions aimed at reducing the problem. Drugs Aging 2012;29:15-30.

42 Markota M, Rummans TA, Bostwick JM, et al. Benzodiazepine use in older adults: dangers, management, and alternative therapies. Mayo Clin Proc 2016;91:1632-9.

43 Ballokova A, Peel NM, Fialova D, et al. Use of benzodiazepines and association with falls in older people admitted to hospital: a prospective cohort study. Drugs Aging 2014;31:299-310.
44 Leipzig RM, Cumming RG, Tinetti ME. Drugs and falls in older people: a systematic review and meta-analysis: I. psychotropic drugs. J Am Geriatr Soc 1999;47:30-9.

45 Carroll NV, Slattum PW, Cox FM. The cost of falls among the community-dwelling elderly. J Manag Care Pharm 2005;11:307-16.

46 Florence CS, Bergen G, Atherly A, et al. Medical costs of fatal and nonfatal falls in older adults. J Am Geriatr Soc 2018;66:693-8.

47 Busato A, Matter P, Künzi B, et al. Geographic variation in the cost of ambulatory care in Switzerland. J Health Serv Res Policy 2012;17:18-23

48 Camenzind PA. Explaining regional variations in health care utilization between Swiss cantons using panel econometric models. BMC Health Serv Res 2012;12:62.

49 Panczak R, Luta X, Maessen M, et al. Regional variation of cost of care in the last 12 months of life in Switzerland: Small-area analysis using insurance claims data. Med Care 2017;55:155-63.

50 Wertli MM, Reich O, Signorell A, et al. Changes over time in prescription practices of pain medications in Switzerland between 2006 and 2013: an analysis of insurance claims. BMC Health Serv Res 2017;17:167.

51 Davies J, Rae TC, Montagu L, et al. Long-term benzodiazepine and Z-drugs use in England: a survey of general practice [corrected]. $\mathrm{Br} \mathrm{J}$ Gen Pract 2017;67:e609-13.

52 Maust DT, Kales HC, Wiechers IR, et al. No end in sight: benzodiazepine use in older adults in the United States. J Am Geriatr Soc 2016;64:2546-53.

53 Agarwal SD, Landon BE. Patterns in outpatient benzodiazepine prescribing in the United States. JAMA Netw Open 2019;2:e187399.

54 Sirdifield C, Anthierens S, Creupelandt H, et al. General practitioners' experiences and perceptions of benzodiazepine prescribing: systematic review and meta-synthesis. BMC Fam Pract 2013;14:191.

55 Anthierens S, Habraken H, Petrovic M, et al. The lesser evil? initiating a benzodiazepine prescription in general practice: a qualitative study on GPs' perspectives. Scand J Prim Health Care 2007;25:214-9. 